\title{
Pedagogical Implications of Using Discussion Board to Improve Student Learning in Higher Education
}

\author{
Amani Alghamdi ${ }^{1}$ \\ ${ }^{1}$ University of Dammam, Saudi Arabia \\ Correspondence: Amani K. Hamdan Alghamdi, College of Education, University of Dammam, Dammam, Saudi \\ Arabia. Tel: 966-013-3337002. E-mail: akhalghamdi@ud.edu.sa
}

Received: July 17, 2013 Accepted: August 18, 2013 Online Published: September 22, 2013

doi:10.5539/hes.v3n5p68 URL: http://dx.doi.org/10.5539/hes.v3n5p68

\begin{abstract}
This study reports on the pedagogical implications of using the Blackboard feature Discussion Board (DB) to improve students' learning in higher education. The study sample included three sections of female students - a total of 155 students - in an undergraduate course at an international university in Saudi Arabia. The impact of using DB on first-year female students' achievement was assessed through quantitative analyses of pre- and post-tests. The effect of DB on students' attitudes was ascertained by means of qualitative analyses of students' responses to a post-treatment questionnaire. The results indicated that students in the experimental group showed a greater degree of improvement in test scores than those in the control group, and that posting to Blackboard was positively related to improvement among those in the control group but not among those in the experimental group.
\end{abstract}

Keywords: blended learning, distance education, Blackboard, Discussion Board, higher education, class online discussion, online class discussion, collaboration, Saudi female students

\section{Introduction}

Online communication is becoming an essential element of higher education in many parts of the world. Many studies have discussed the advantages, disadvantages and limitations of using online learning, blended learning, web-based learning, virtual learning environments and online discussions. Al-Hosan and Oyiad (2010) refer to one major advantage of online learning: it offers an individualized learning experience that fulfills the educational needs of students with different learning styles (p. 798). Virtual learning environments also offer flexibility in terms of time and place (Barbour \& Reeves, 2009). Another of their most important advantages is the ease with which the information provided can be continuously modified, thus helping to make learning more enjoyable and individualized (Al-Shanak \& Doumi, 2009). As explained by Garrison and Anderson (2003), online learning is emerging as "a practical necessity in the realization of relevant, meaningful, and continuous learning" (p. 23).

Various studies have pointed to the importance of communication between instructors and students. Al-Fadda and Al-Yahya (2010) describe the use of blogs to encourage pre-class reading assignments and to enhance learning and discussion during class (p. 105). They found blogs to be an effective tool for encouraging students to do pre-class readings and to engage in post-class reflections. This research is also valuable for its evaluation of students' general attitudes towards the use of blogs in higher education.

Online learning environments are increasingly becoming a staple component of teaching and learning in higher education. The influence of these environments on the nature of the communication that takes place within courses has huge pedagogical implications (Wilkinson \& Barlow, 2010, p. 1). In this paper I demonstrate that the use of Discussion Board (DB), which is a feature of Blackboard (BB), to help students share and debate can be a catalyst for the transformation of educational practices for the better if it is supported by educational pedagogies that enhance critical thinking and metacognitive learning skills.

\section{Method}

Religion and culture in Saudi Arabia shape not only people's attitudes, practices and behaviours, but also their construction of the reality of their life. Similarly, the social environment, in the case of the integration of online and face-to-face learning, exerts considerable influence on students' perceptions. This makes social-constructivism theory appropriate for this study's attempt to understand the perceptions of instructors and 
students in regard to blended learning in Saudi society.

The main research question concerns how the use of DB as a pedagogical tool in higher education is related to changes in test scores. Three groups of first-year university students participated in the study: two groups employed DB to discuss the course readings prior to class and to reflect afterwards on the issues and cases that had been discussed in the classroom, while the third group did not have this requirement and relied on the set textbooks only. The impact of DB on these students' achievement was ascertained through quantitative analyses of pre- and post-tests. The effect on students' attitudes of the use of DB was determined based on qualitative analyses of students' responses to a post-test questionnaire.

\subsection{Participants}

The total of 155 female second-year university students who were enrolled in the Professional Development and Competencies course were divided into three groups: A, B and C according to their registration. These students were majoring in interior design, computer science and business administration at a private university in Saudi Arabia. They were concurrently taking other courses outside their field of specialization and were using BB as a learning medium with which to connect with their instructors.

All the subjects were native speakers of Arabic; 95 percent were Saudi nationals and 5 percent were Pakistani or Indian nationals. Their median age was 18 years, with a range of 17-19 years. The Saudi students all had six years of EFL instruction in grades 6-12 prior to their admission to university, and they had all enrolled in a preparatory year to improve their English. The non-Saudi students had attended international schools in which the medium of instruction was English. Most of the instructors at the university were female except for those in a few business courses. The findings of the present study therefore cannot reliably be generalized to male students taking the same Professional Development and Competencies course and studying from the same textbooks.

All the students registered for the course were required to appear on BB for the instructor with whom they were taking the course. Two groups, experimental and control, were formed. The experimental group was taught and then asked to engage in a group discussion and to answer questions, whereas the control group was taught the same subject and followed the same teaching method but was not involved in the discussion group. Both groups therefore used the same textbooks, were exposed to the same in-class content and instruction, and were subject to the same grading scheme. In addition to face-to-face in-class discussions, the experimental group was exposed to discussions on the online DB. The control group was not exposed to the online DB and the discussions therein. The students in the experimental group had prior experience with using BB for checking their grades and submitting their assignments online but they had no prior experience with DB.

\subsection{Pre-Test Phase}

The experimental and control groups were exposed to the same content in class and to the same grading method - except for the part related to the DB.

The blended learning model that was utilized integrates online instruction ( 70 percent) with face to-face instruction (30 percent). Online discussion was used for the purposes of this study as an obligatory assessed element of online instruction. Other elements of blended learning were employed in the research, but these are beyond the scope of the present paper. In each blended course, students were asked to regularly participate in about four threads initiated by the course instructor.

\subsection{Online Discussion Board}

The experimental group used an online DB, which is a feature of BB. DB was employed to discuss questions related to the course that were posted on a weekly basis. The questions were varied according to the chapters that the students were required to read every week; samples of these and of the answers provided are set out in Appendix A. In the first week of classes, the students received a tutorial on using DB. Since the students were already familiar with the BB system, this task was easily accomplished. The online DB and the importance of participating in it were emphasized in the classroom. Throughout the semester, the instructor (i.e., the author) served as an online facilitator. She posed questions and responded to individual students' needs, comments, and requests regarding particular issues. She also ensured that she responded to all students' queries and that she commented on students' viewpoints about the value of discussion. The instructor sent public and private messages to encourage the students to interact, communicate and post answers to the facilitator and their colleagues. She posted questions and discussion topics every week. 


\subsection{Procedure}

This study took place in 2011. At the beginning of the fall semester in the first week of the course, the experimental and control groups were pre-tested and a questionnaire was distributed to both regarding the various issues that were going to be covered in the course. The pre-test was distributed to ascertain the students' thoughts and perspectives about participating in the online discussion board. It was necessary to ascertain the students' thoughts and perspectives before the course so that these could be compared with their thoughts and perspectives at the end of the course. All students - in both the experimental and control groups - took the same pre-test, which consisted of questions covering the topics to be studied.

Students in both groups completed all assignments, but the experimental group had the DB as an extra ungraded assignment; the students' participation was considered their recurring homework to be completed after attending class. Over the course of their participation in the DB, the instructor monitored the students' work and the ways in which ideas developed on a weekly basis, as well as provided comments that were related to the discussions and that connected them to the course readings. Technical errors, such as those pertaining to spelling, grammar and sentence structure, as well as other errors, were highlighted individually though no corrections were provided. Instead, the students checked and corrected their language mistakes on their own in order to enhance and reinforce their learning. The instructor also checked for plagiarism. Extra credit was offered to selected students at the end of the term as a bonus. The participants were informed at the beginning of the course that those who expressed themselves with minimal mistakes (so as to encourage them to review their answers before posting them on the DB) would receive a bonus in the form of an extra credit at the end of the course.

Tests and assignments were graded and returned to the students with comments on their individual strengths and weaknesses. An online discussion took place each week in which I posted a question that encouraged students to consider the topics covered in the class list or that was triggered by something discussed in class in previous weeks. I allowed the students to answer questions posted by the instructor or provided to them by their classmates; the answers were discussed online. Students were encouraged to participate, and 10 percent of their grade which was extra to the overall grade was based on their participation in the weekly DB, as discussed above. This means that those who did not participate were not penalized in any way.

At the end of the semester, both groups took the same post-test, which covered all the topics studied throughout the semester. The purpose of the post-test was to collect the students' points of view about participating in the discussion board as well as their rating of their experience. These covered, but were not limited to, the following issues:

- Ethics;

- Discipline-specific ethics;

- Opportunities, demands and career path in a field;

- Discipline-specific communication skills;

- Professional-accreditation requirements;

- Communicating in a diverse world;

- Ways of developing consciousness of diversity;

- Personal and social barriers to success;

- Professional accreditation;

- Ways of creating career-specific goals and objectives;

- Approaches to becoming professionally competent;

- Career paths in future workplaces;

- Strategies and techniques for negotiation;

- Asserting oneself; and

- Conflict resolution.

The pre- and post-tests of both groups were anonymously graded by the instructor. ID numbers were used instead of students' names. Questions were graded one at a time for all the students.

At the end of the course, each student answered an open-ended questionnaire, which consisted of the following questions: 
1. How did you find the DB?

2. What did you like about the course? What did you not like?

3. Did your knowledge of the content improve as a result of using the online discussion forum? Explain how.

4. Did it make any difference in learning more about topics relating to Professional Development and Competencies?

5. If you did not post any responses or paragraphs in the online course, what led you to make this decision?

6. What problems or difficulties did you face in using the DB? How were those problems solved?

7. How often did you go online to post, answer or communicate in the DB?

8. How much time did you spend posting each point of view to the DB?

9. Would you like to use the DB again in a similar course in the future? Why?

\subsection{Test Validity and Reliability}

The pre- and post-tests had face validity as they aimed to assess the students' knowledge of the course content and their ability to discuss various aspects of the course case studies. Additionally, the tests sought to identify the skills of the students prior to their exposure to the discussion board. For instance, the students were asked how they view dealing with people of a different cultural background and whether they find it important to work with people from their own cultural group. Some students answered that it would be much easier for them to work in an environment that is a monoculture, while other students answered that it would be both challenging and a positive learning experience to mingle with a diverse group of workers from different ethnicities. The discussion points in the post-test were comparable to those covered in the textbooks and in class.

The concurrent validity of the post-test was determined by correlating students' scores on the post-test with their grades on the final test and in the course as a whole. The correlation coefficients were 0.78 and 0.72 respectively. Since the author was also the instructor of the experimental and control groups and the scorer of the pre- and post-test essays, estimates of inter-rater reliability were necessary. A 40 percent random sample of the pre- and post-test papers was selected and double-scored. Another colleague - an assistant professor of education and curriculum - scored the pre- and post-test samples. The scoring procedures were explained to her, and she followed the same scoring procedures and used the same answer key as the author. The marks given by the rater were correlated with those of the researcher. The inter-rater correlation was 0.99 for the post-test. Furthermore, the examinees' reliability was calculated using the Kuder-Richardson formula (Kuder \& Richardson, 1937). The examinee reliability coefficient for the post-test was 0.85 .

\section{Data Analysis}

The mean, median, standard deviation, standard error and range were calculated for the pre- and post-test scores for the experimental and control groups. Multiple regressions were run using the post-test scores as the response variable, the group as the independent variable and the pre-test scores as a covariate. This correction resulted in the adjustment of group means for pre-existing differences caused by sampling error and by reduction of the size of the error variance of the analysis. In order to enable the researcher to determine the degree to which each group had made progress as a result of the addition of the new forms of instruction, a within-group t-test was calculated for each group on the difference between the pre- and post-test scores. To find out whether there was a relationship between the students' post-test scores and their frequency of using the DB, each student's post-test score was correlated (using the Pearson correlation formula) with the number of responses that they posted on the BB.

\section{Results}

The results of the t-test showed significant differences between the experimental and control groups in terms of their knowledge of the Professional Development course relative to before the beginning of the Blackboard discussions $(\mathrm{t}=0.27, \mathrm{df}=10.7 .11, \mathrm{p}=0.78)$; because of unequal variances, the Satterthwaite correction was used. The experimental group outperformed the control group (median $=40$ percent and 55 percent respectively). There were larger variations among students in the experimental group than in the control group, as shown in the standard deviation values presented in Table 1. 
Table 1. Distribution of pre-test scores of the experimental and control groups

\begin{tabular}{lccllll}
\hline & $\mathrm{N}$ & Mean & Median & Standard Deviation & $\begin{array}{l}\text { Standard } \\
\text { Error }\end{array}$ & Range \\
\hline $\begin{array}{l}\text { Experimental } \\
\text { group }\end{array}$ & 65 & 5.26 & 6 & 1.30 & 0.15 & $2-7$ \\
$\begin{array}{l}\text { Control } \\
\text { group }\end{array}$ & 90 & 5.21 & 5.00 & 0.91 & 0.10 & $4-8$ \\
\hline
\end{tabular}

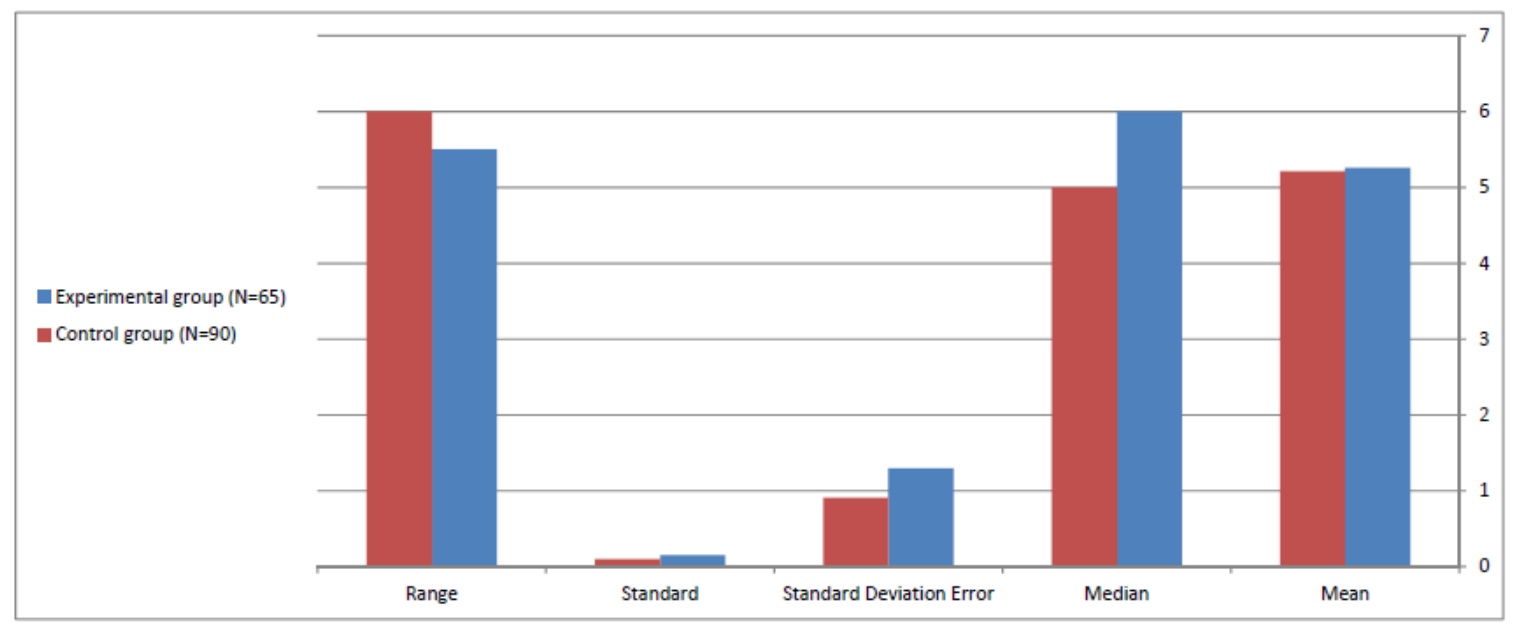

Figure 1. Graphical representation of Table 1

\subsection{Pedagogical Implications of Using the DB in Learning}

\subsubsection{Effect of the DB on Students' Achievement}

Table 2 shows that students in the experimental group scored higher than those in the control group on the post-test (median $=9$ and 6 respectively), with similar variations observed among students in the experimental and control groups $(\mathrm{SD}=0.87$ and 0.97 respectively).

Table 2. Distribution of post-test scores of the experimental and control groups

\begin{tabular}{|c|c|c|c|c|c|c|}
\hline & $\mathrm{N}$ & Mean & Median & $\begin{array}{l}\text { Standard } \\
\text { Deviation }\end{array}$ & $\begin{array}{l}\text { Standard } \\
\text { Error }\end{array}$ & Range \\
\hline $\begin{array}{l}\text { Experimental } \\
\text { group }\end{array}$ & 65 & 8.75 & 9 & 0.87 & 0.11 & $6-10$ \\
\hline $\begin{array}{l}\text { Control } \\
\text { group }\end{array}$ & 90 & 5.50 & 6 & 0.97 & 0.10 & $4-8$ \\
\hline
\end{tabular}




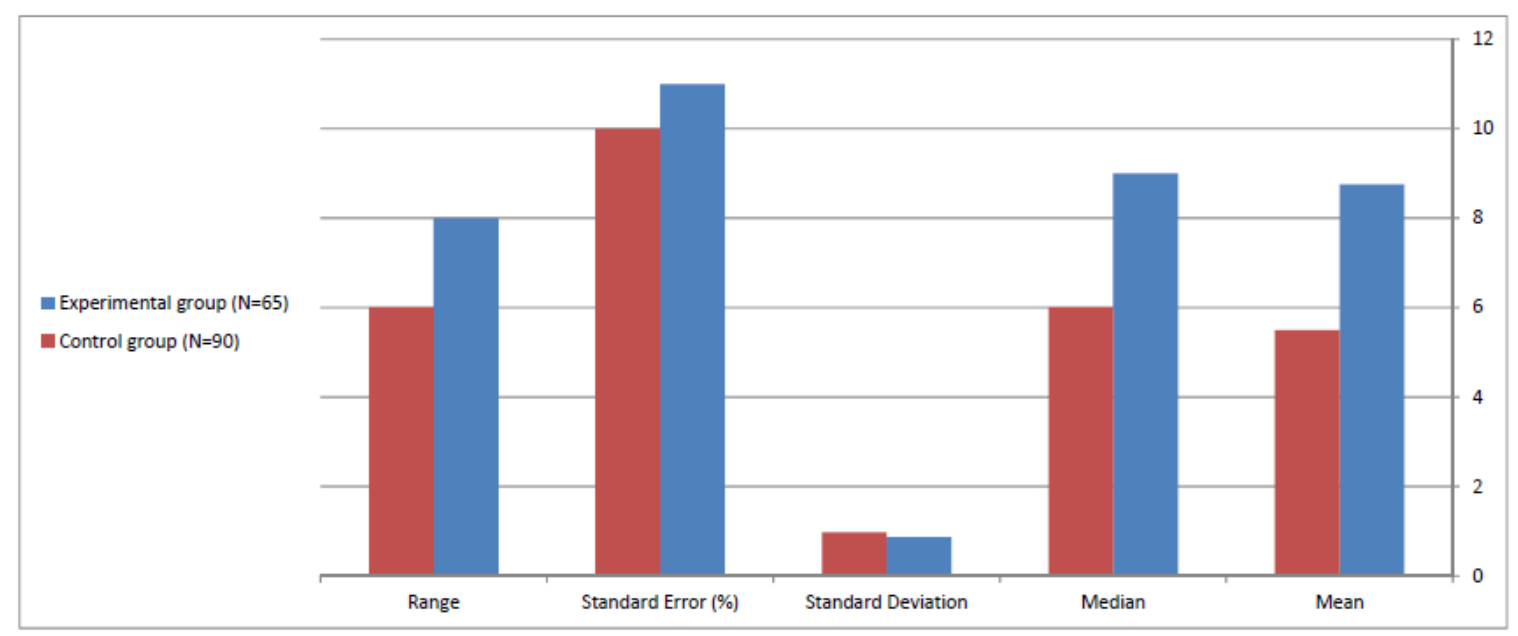

Figure 2. Graphical representation of Table 2

Multiple regressions showed that this difference was significant, even after controlling for the pre-test score. The predicted value for the experimental group was 3.15 points higher, than the controlled for the pre-test score. For this model, $\mathrm{R}^{2}=0.88$. (See Table 3 )

Table 3. Regression model of post-test scores on group and pre-test scores

\begin{tabular}{lrrrr}
\hline Parameter & Estimate & Standard Error & T Value & P value \\
\hline Intercept & 2.41 & 0.26 & 9.28 & $<.0001$ \\
Pre-test & 0.61 & 0.05 & 12.69 & $<.0001$ \\
Group E & 3.15 & 0.11 & 29.86 & $<.0001$ \\
Group C & & Reference category & \\
\hline
\end{tabular}

The addition of a "messages posted" entry to the model led to very little improvement in $\mathrm{R}^{2}$, but this entry was nearly statistically significant. (See Table 4)

Table 4. Regression model of post-test scores on group, pre-test scores and messages

\begin{tabular}{lrrrr}
\hline Parameter & Estimate & Standard Error & T Value & P value \\
\hline Intercept & 2.33 & 0.26 & 8.92 & $<.0001$ \\
Pre-test & 0.61 & 0.05 & 12.90 & $<.0001$ \\
Group E & 2.81 & 0.21 & 13.43 & $<.0001$ \\
Group C & & Reference group & & \\
Messages & 0.01 & 0.004 & 1.89 & 0.0611 \\
\hline
\end{tabular}

Students in the experimental group posted more messages than those in the control group (means $=48.40$ and 5.41 respectively; $\mathrm{sd}=17.37$ and 6.85 respectively). This difference was significant: $\mathrm{t}=18.93, \mathrm{df}=78.92, \mathrm{p}<$ 0.0001 . However, while there was a significant relationship between the messages posted and the post-test score for the control group $(\mathrm{r}=0.21, \mathrm{p}=.04)$, there was no significant correlation between the post-test scores of the experimental group and the frequency of using the DB $(r=-0.05, p=0.72)$. This suggests that using the message board or being in the experimental group raised post-test scores, but that posting more messages had little effect within the experimental group. Table 5 shows the total number of discussion messages posted, together with the median and maximum number of messages posted. 
Table 5. Distribution of discussion messages posted by experimental group members

\begin{tabular}{llll}
\hline Examples of topic & Total number of group messages & Median & $\begin{array}{l}\text { Maximum number of } \\
\text { individual messages }\end{array}$ \\
\hline Diversity consciousness & 100 & 10 & 4 \\
Negotiation & 80 & 6 & 2 \\
Anger management & 130 & 9 & 4 \\
in the workplace & & & \\
\hline
\end{tabular}

\subsubsection{Effect of the DB on Students' Attitudes and Related Skills}

Analysis of the students' comments and responses to the post-test questionnaires revealed positive attitudes towards the DB. All students found the online DB to be useful and engaging. It heightened their motivation, raised their self-esteem and made them more capable of discussing all issues related to the class without feeling embarrassed. The researcher wanted to experiment using the DB, but could not make it mandatory for the entire group and could not allocate a portion of the course grade to it. A great improvement was documented not only in how students tackled various challenging issues but also in their ability to make connections to their own lives.

\subsection{Limitations}

Among the negative aspects of using the DB in the present study was the fact that some students would only post responses if prompted to do so by the researcher or if the instructor posted a sample response for each new topic. Some students started new threads dealing with the same topic rather than post their responses under the original topic heading. Some wrote "thank you" notes and compliments instead of real responses. Others just browsed and read messages rather than actually contribute a posting.

The use of the Internet as a learning tool was not part of some students' culture. Some were accustomed to using BB to submit assignments and to check their syllabus and course calendar, but they had not previously explored many of its features and they were surprised to be asked to engage in the DB. They indicated that they were not interested in doing their homework on the DB and that they preferred to use the Internet for entertainment purposes only.

\section{Discussion and Conclusion}

The Professional Development and Competencies course contains many new concepts that students may have been encountering for the first time. Significant differences were found between the experimental and control groups in terms of their level of understanding of these concepts. The students in the experimental group were much better able to give examples of the various topics discussed as measured by the post-test, which suggests that achievement in the experimental group improved as a result of the blending of the online DB with in-class discussion. This is evidence indicating that the use of online discussion as a supplement to in-class discussion improves students' achievement and learning in higher education, at least in this particular context.

The findings of the present study also indicated that students who were not enrolled in the course but who participated in the DB achieved better results in their tests than those who chose not to post comments. The latter did better than those students who did not have access to the DB or to any online communication (the control group). This finding is consistent with those of prior studies that have used other forms of technology in the teaching of various subjects. Al-Jarf (2005) focused on students' learning of grammar and found that blended learning was beneficial and improved students' grammar practices significantly. In Cheng et al. (2004), students' acquisition of difficult physics concepts was found to have been enhanced through the use of online learning tools. Richards-Babb et al. (2011) also found that attitudes to online homework were generally positive, with a large majority of students viewing online homework favourably (80.2 percent), and as being worth the effort (83.5 percent), relevant (90.5 percent), challenging (83.4 percent) and thought-provoking (79.0 percent) (p. 92). Moreover, Felix (2001) reported that students were positively disposed towards working on the web and that they found it useful, with the majority preferring to employ it as a supplement to face-to-face teaching.

Some students in this study showed interest in reading and engaging in the DB because it gave them the opportunity to express their ideas, to discuss challenging concepts that they had read in the textbooks before class, and to reflect on points mentioned in the classroom. Some of the issues raised on the DB were controversial in nature and, although it was difficult for some students to participate in the discussion of these 
topics in the classroom, they were able to fully engage with them in the DB.

While this study attempted to shift the focus from a summative assessment, Lineweaver (2010) previously developed an online discussion assignment and found that this had a limited effect on examination performance. In Lineweaver's (2010) study, the students who completed online discussions were more likely to read their textbooks ahead of class and to report reading them more carefully, particularly late in the semester, a finding that aligned with the results of the present study.

The present study also revealed some positive effects of blended learning (combining online and face-to-face instruction) on students' attitudes towards their course. They spoke positively about the experience with other students who were not participating in it. This study's finding is consistent those of similar studies, such as Hamdan $(2010,2012)$ and Wilkinson and Barlow (2010), in which students indicated that engaging in online discussion with their colleagues and instructors helps to change their perceptions of and perspectives on their learning.

Online discussion breaks down barriers for shy students who are not accustomed to participating in classroom discussion. Rosenberg (2001), for instance, found that, even though blended learning has a range of interpretations, there is a consensus around the idea that it constitutes a combination of face-to-face sessions, e-learning and text-based learning materials (p. 12). The mix can be in different proportions and both text-based and digital learning may occur within face-to-face interactions. Wilkinson and Barlow (2010) found that:

There have been many studies investigating the ways in which higher order thinking and increased cognitive processing can be encouraged in collaborative learning environments such as Discussion Boards (e.g., Schellens \& Valcke, 2005; Kanuka \& Garrison, 2004; McLoughlin \& Mynard, 2009) but few, if any, have tested this in non-traditional, distance learners (p. 29).

This became evident in this study in terms of the students' performance in the discussions and in terms of the results in the final examinations.

It seems that students in the Saudi context would rather participate in activities that provide them with grades over those that improve their skills but do not directly enhance their grades. Al-Jarf (2005) found that "Many Saudi college students do extra work for grades only. If online learning is not part of tests and grades, they will not participate" (p. 20). This also appeared to be the case in this study. As such, students who had the opportunity but did not participate in the DB were in effect choosing not only to limit their experience in the course but also to limit their understanding of the course concepts.

According to Wilkinson and Barlow (2010), some of the difficulties associated with using online discussion are related to time management: "One of the main barriers to engagement with Discussion Boards for our participant group was time. Due to their high work commitments, many were frustrated that they lacked the time to properly engage with these activities" (p. 33). This factor also applied to many of the students in this study. On the other hand, the results showed that those who did engage found that the time that they spent discussing the material was of value to them. Another issue that has been raised in the academic literature is that "eLearning environments pose such disadvantages as hindrance of the socialization process of individuals, lack of sufficient recognition between the teacher and the learner and limitations concerning the communication among learners" (Akkoyunlu \& Soylu, 2008, p. 183). However, this was not the case in this study, as many students indicated that they enjoyed the DB and engaging outside the class with their instructor and their classmates.

Finally, among the study's most important conclusions is that the attainment level of the experimental-group students, who had engaged with the DB, increased beyond that of their counterparts who had not participated in the DB within the framework of conventional education. There were also differences in the results of the pre-test and the post-test to which the students in the experimental group were subjected. The results are in favour for the post-test, which adds strong support for the effectiveness of learning enhanced by the use of the DB.

The present study recommends that instructors at all levels, and particularly those in higher education, engage students in Discussion Boards and make use of a technology that is here to stay and will continue to evolve. Nevertheless, careful planning of a pedagogy that is suited to the learning objectives remains a significant factor for ensuring the success of the course and the teaching:

Web-based learning (WBL) methodologies are becoming increasingly popular in higher education. Both students and instructors gain significant benefits from Web-based learning environment. However, appropriate learning objectives and pedagogical strategies are key attributes to stimulating the creation of effective e-learning environments (Jia, 2005, p. 1). 


\section{References}

Akkoyunlu, B., \& Soylu, M. Y. (2008). A study of students' perceptions in a blended learning environment based on different learning styles. Educational Technology \& Society, 11(1), 183-193.

Al-Fadda, H., \& Al-Yahya, M. (2010). Using web blogs as a tool to encourage pre-class reading, post-class reflections and collaboration in higher education. ERIC Document Reproduction Service No. ED511312.

Al-Hosan, A., \& Oyaid, A. (2012). Towards identifying quality assurance standards in virtual learning environments for science education. Pertanika Journal of Social Sciences \& Humanities, 20(3), 797-828.

Al-Jarf, R. S. (2005). The effects of online grammar instruction on low proficiency EFL college students' achievement. Asian EFL Journal, 7(4), 166-190.

Al-Shanak, K., \& Doumi, H. (2009). Foundations of e-learning in science education. Amman, Jordan: Dar Wael for Publishing and Distribution.

Cheng, K., Thacker, B., Cardenas, R., \& Crouch, C. (2004). Using an online homework system enhances students' learning of physics concepts in an introductory physics course. American Journal of Physics, 72(11), 1447-1453. http://dx.doi.org/10.1119/1.1768555

Felix, U. (2001). A multivariate analysis of students' experience of web based learning. Australian Journal of Educational Technology, 17(1), 21-36.

Garrison, D. R., \& Anderson, T. (2003). E-learning in the 21st century: A framework for research and practice. London: Routledge/Falmer. http://dx.doi.org/10.4324/9780203166093

Hamdan, A. (2010). E-Learning and teaching: The need for clear pedagogy. In T. V. Yuzer, \& G. Kurubacak (Eds.), Transformative learning and online education: Aesthetics, dimensions and concepts (pp. 111-126). New York: IGI Global. http://dx.doi.org/10.4018/978-1-61520-985-9.ch008

Hamdan, A. (2012). The cultural aspects of e-learning and the effects of online communication: A critical overview. In U. Demiray, G. Kurubacak, \& V. Yuzer (Eds.), Meta-communication for reflective online conversations: Models for distance education (pp. 184-204). New York: IGI Global.

Hamdan, A. (2012). The cultural aspects of e-learning and the effects of online communication: A critical overview. In G. K. Ugur Demiray, \& T. Volkan Yuzer (Eds.), Meta-communication for reflective online conversations: Models for distance education (Vol. 1, p. 187). New York: Information Science Reference (an imprint of IGI Global).

Jia, Y. (2005). Building a web-based collaborative learning environment: Information technology based higher education and training. ITHET 2005, 6th International Conference. 7-9, F2D/7 - F2D/9.

Kuder, G. F., \& Richardson, M. W. (1937). The theory of the estimation of test reliability. Psychometrika, 2, 151-160. http://dx.doi.org/10.1007/BF02288391

Lineweaver, T. T. (2010). Online discussion assignments improve students' class preparation. Teaching of Psychology, 37, 204-209. http://dx.doi.org/10.1080/00986283.2010.488546

Richards-Babb, M., Drelick, J., Henry, Z., \& Robertson-Honecker, J. (2011). Online homework, help or hindrance? What students think and how they perform. Research and Teaching, 40(4), 81-93.

Rosenberg, M. J. (2001). E-learning: Strategies for delivering knowledge in the digital age. New York: McGraw-Hill.

Wilkinson, K., \& Echternacht, L. (1998). Internet homework activities and traditional homework activities: The effects on achievement, completion time, and perception. Delta Pi Epsilon Journal, 40(4), 214-230.

Wilkinson, S., \& Barlow, A. (2010). Turning up critical thinking in Discussion Boards. eLearning Papers, 1(21), $1-12$.

\section{Appendices}

Appendix A

An unedited sample of DB threads on various topics, with students' responses and comments

FROM: [Author]

SUBJECT: Negotiation Skills 
Question: Do personality traits affect negotiation skills? How?

\section{REPLIES}

\section{FROM: Reem XXXX}

Well yes definitely! Personality affects negotiation more than anything. You see, people focus 25 percent on the message that you're delivering, but the focus on 75 percent on the WAY it's delivered. So if a person's personality traits include steadiness, patience, and good-listening skills, along with persuasion abilities then definitely the negotiation will become successful.

\section{FROM: Aala'a XXXX}

Personality traits definitely effect negotiation skills in many ways; because negotiation is also effected by other factors such as the situation and the people who are involved in the negotiation. And for how they react toward these situations, it depends on the individual's personality and way of thinking. For that reason, negotiation skills and strategies are different from one person to another. Thus, negotiation skills are effected by the personality traits.

\section{FROM: Alaa XXXX}

Indeed personality influence many aspects of our life. It reflects personal values and believes. surly, it's one of the main factors that effect the negotiation skills. as it's mentioned in our book (Conflict Management) personality traits definitely has a direct effect on our way of behavior, negotiation and dealing with others. one of the mentioned examples was personality type B is more successful in negotiating with others because of his unique traits flexibility, calm temper and patience. Some people they might be successful in everything except for negotiation because of poor control of emotions. while others knows exactly how to control their emotions and manipulating, persuading and explaining their opinions smartly.

people with high flexibility and high control of emotions they win the case easily because they know what they want, how to explain it, how to persuade the others and they know precisely when they should stop or stick to their opinions.

FROM: [Author]

SUBJECT: Knowing about others

Question: Do you have interest in the knowledge of others and of their worlds?

\section{REPLIES}

\section{FROM: Samar XXXX}

People are different not only in culture but also in the same culture you can fine people whose opinions are different than me and learning about other people will make aware about others and not all of people will react the same as me or my friends. i love learning about others and their different points of view or their culture it is empowering and gives you knowledge about different people

\section{FROM: Sukaina XXX}

In fact, taking a step back and observing people actions is very useful method to learn about myself and develop my skills. by observing I'm going to notice their mistakes and their weaknesses so I learn immediately if I was doing such a thing or having such a trait I'd be alerted that I can change something about myself.it helps to discover who I am and what personality trait do I have.

\section{FROM: Mira XXX}

Sometimes it is very important to learn from others because it helps you realize issues that you have not paid attention to or not given any importance. In fact, they may be important and we should know have to change or improve from others' mistakes so that we do not have to do the same mistakes again. 


\section{FROM: Asmaa XXX}

Learning about others helps me in recognizing or noticing things about myself that I am not aware of. For example, in certain situations I would act in a particular way that may be not right. I my self can not see it wrong. However, when I see someone else acting the same away in the exact same situation, I will be able to see, criticize and analyze the action from an outsider eye. I then learn about myself from other people's behaviors and actions.

FROM: [Author]

SUBJECT: Controlling anger in the workplace

Question: Do you have to manage your anger in the work place? Why?

\section{REPLIES}

\section{FROM: Anwar XXX}

When you control your anger you receive less problems in your life, but anger is a normal emotion, because when you express your anger sometimes it makes you feel relieved and comfortable. there are some ways that could help people manage and control their anger; such as counting tell 10 and take a long breath, maybe having some yoga classes and even by saying (not God but Allah and Mohammed is his messenger) by doing one of these things you will feel better and you will control your anger.

\section{As Howard Martin said,}

It simply doesn't matter whether your anger is justified or not. The body doesn't make moral judgements about feelings; it just responds.

\section{FROM: AlAnood XXX}

In my point of view I think I have to learn how to mange my anger because; being angry does not do any good for my health and my relationship with others. The ways I mange my anger are: taking a deep breath, sit down if I was standing or lie down if I was sitting just like prophet Mohammad peace be upon him said. And always remember patience is one of the most important ingredient for a happy and anger free life.

\section{FROM: Hadeel XXX}

Because when a person is angry, he can't control what he's saying, he wouldn't even feel it because he's angry, that's why a lot of people we see them get angry from a situation or a certain attitude, they always regret it.. that's why anger management is VERY important.

\section{Appendix B}

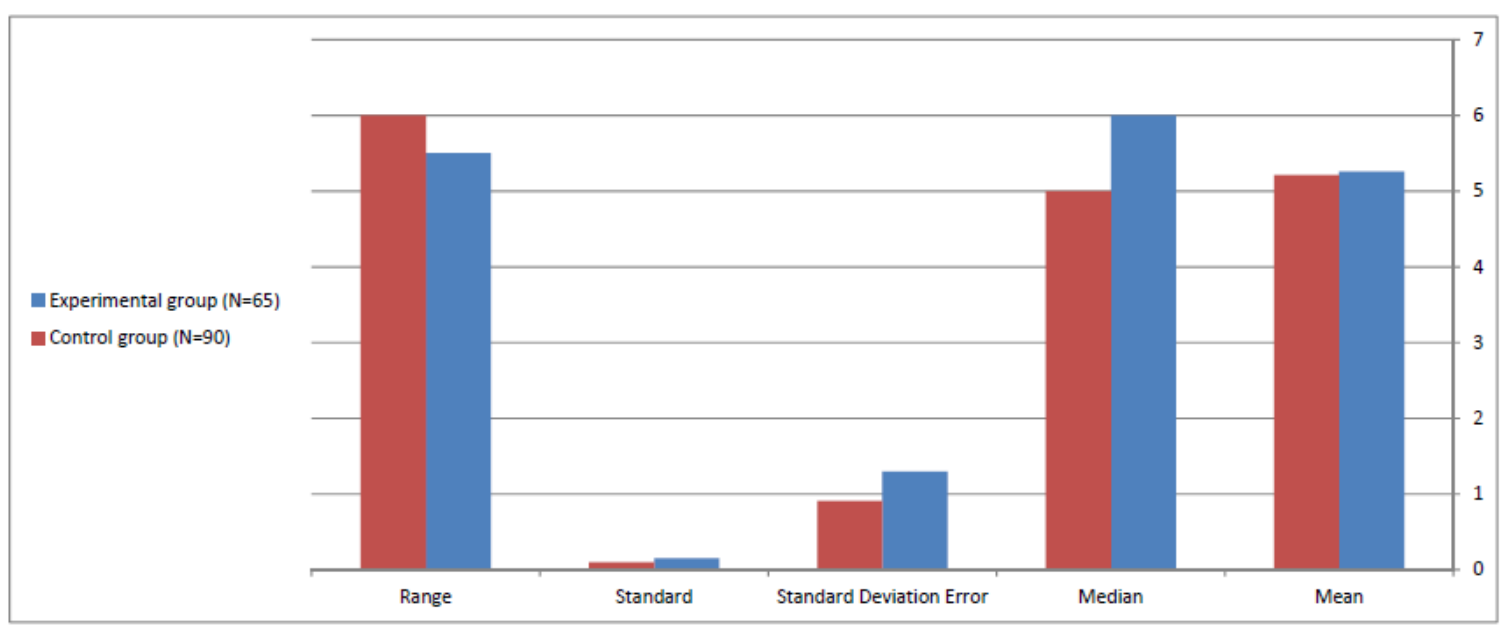

Figure 3 


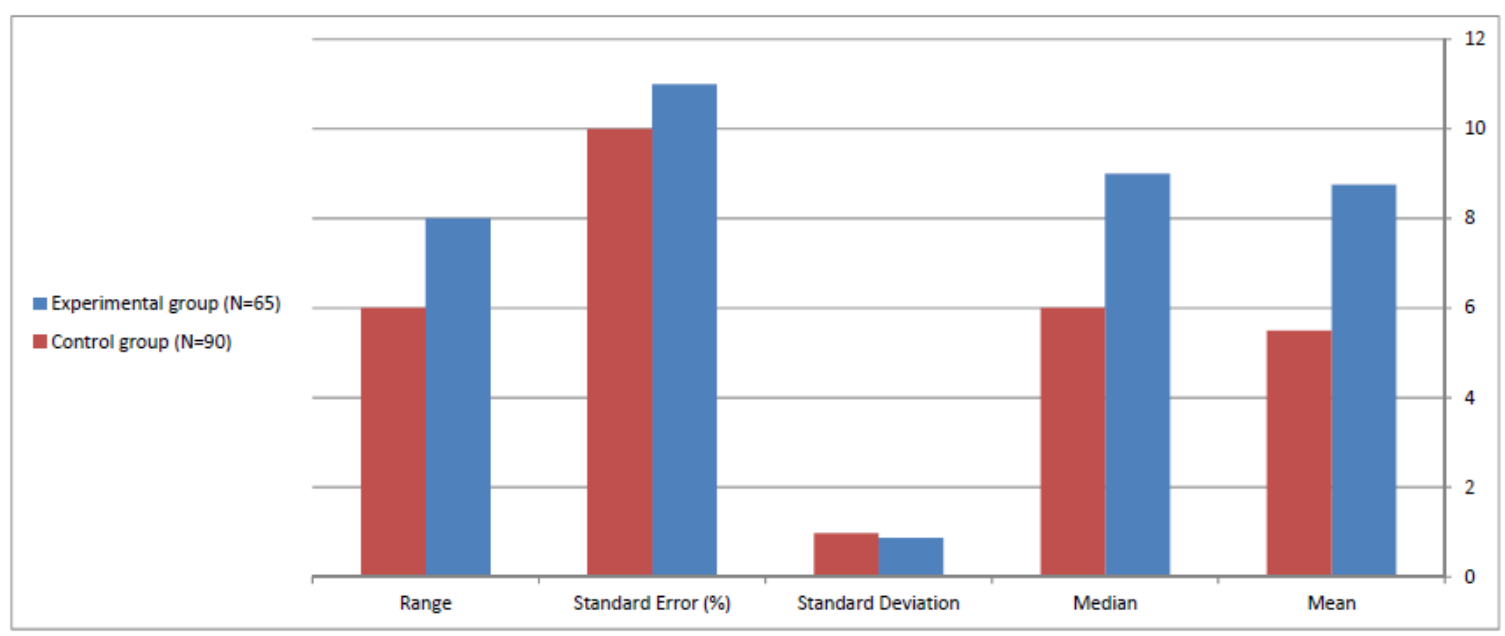

Figure 4

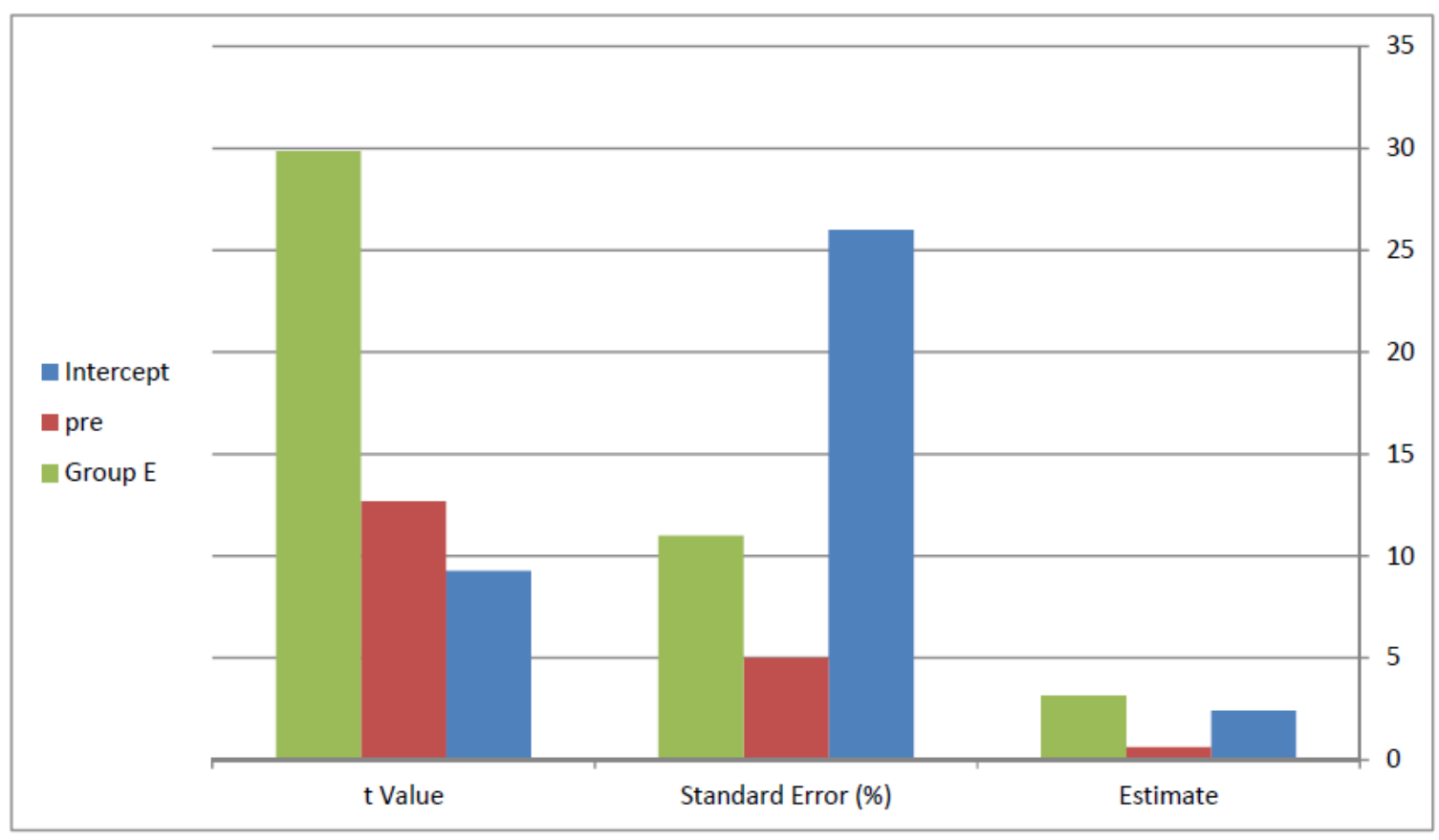

Figure 5 


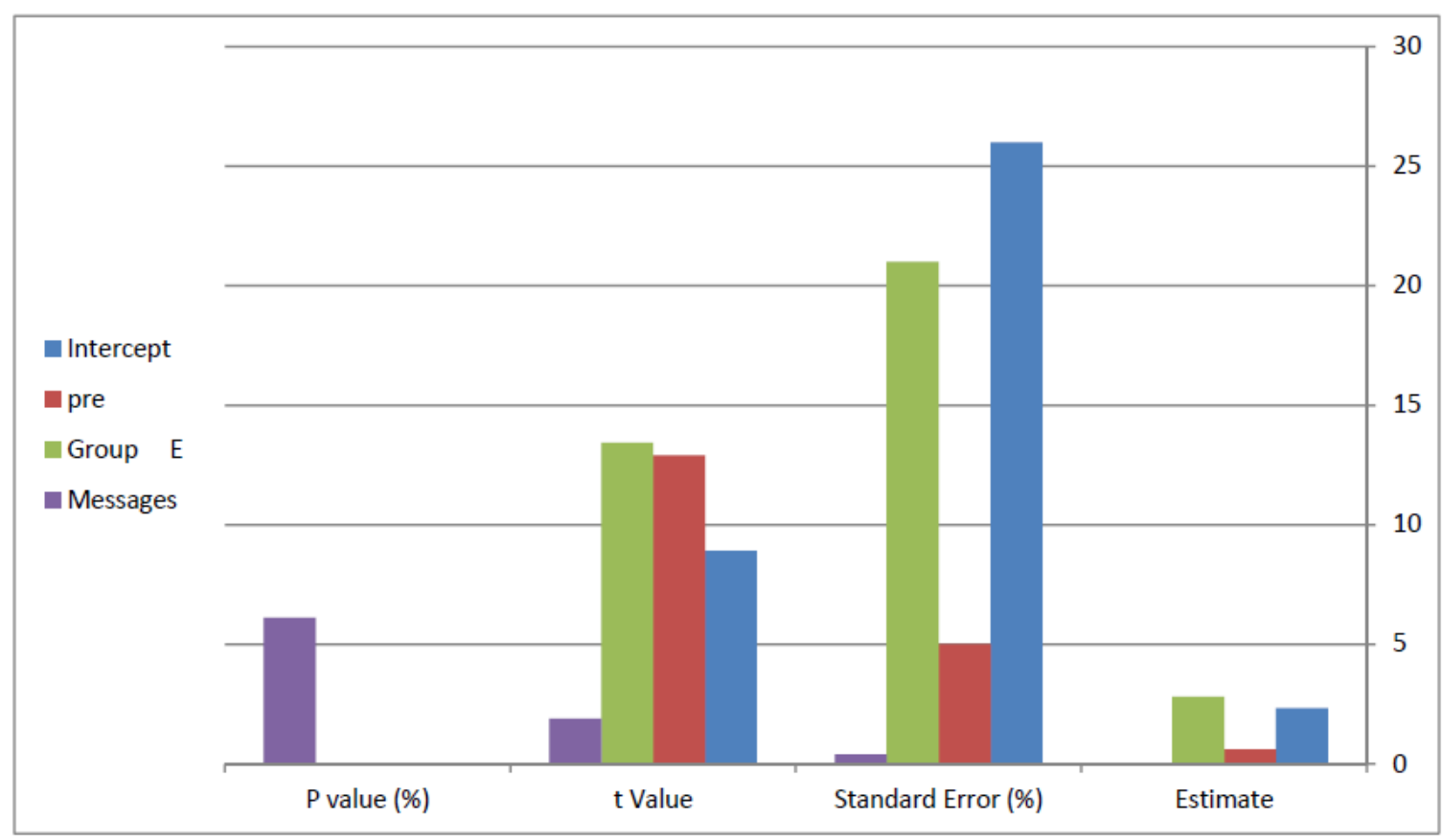

Figure 6

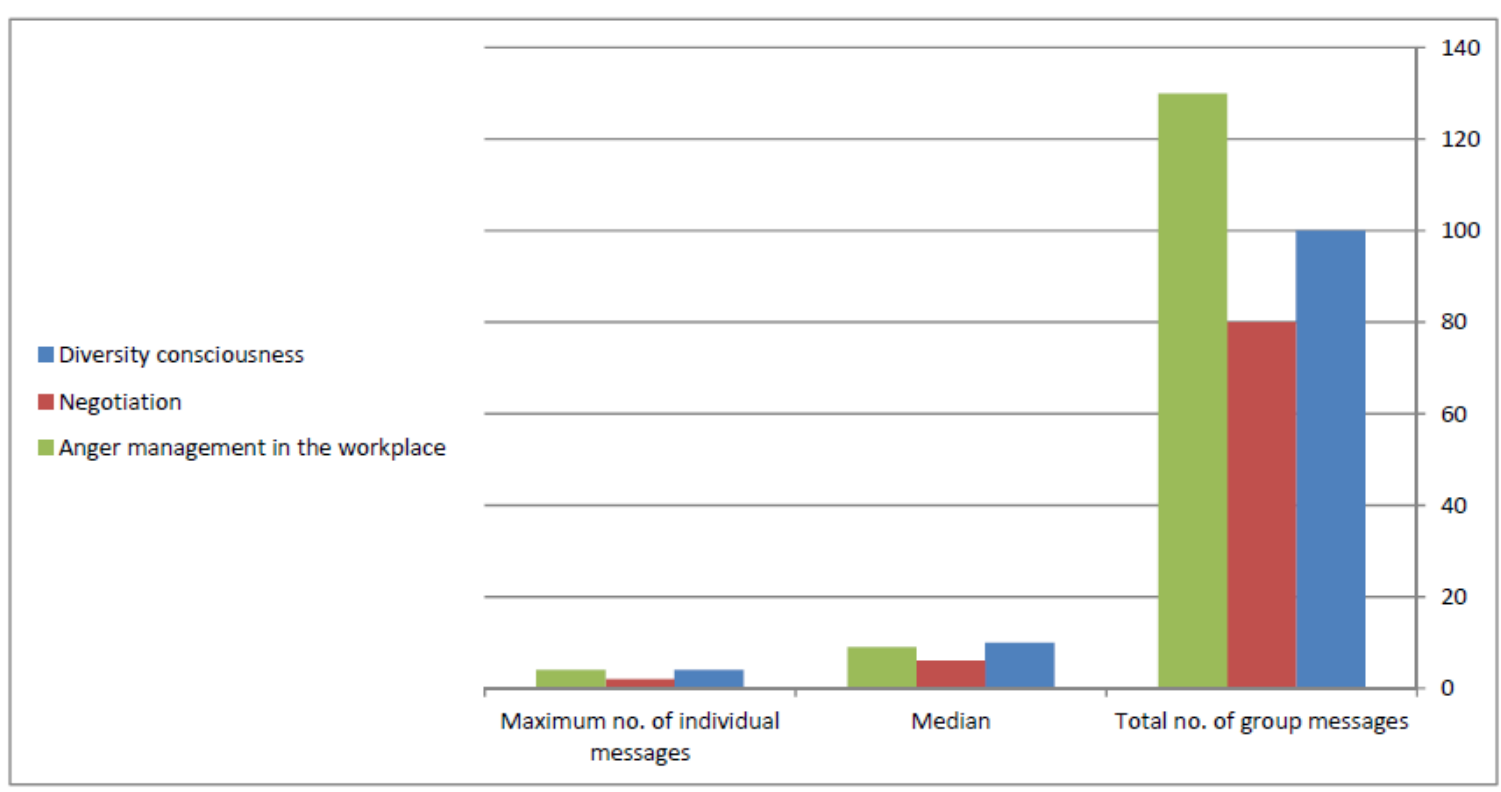

Figure 7

\section{Copyrights}

Copyright for this article is retained by the author(s), with first publication rights granted to the journal.

This is an open-access article distributed under the terms and conditions of the Creative Commons Attribution license (http://creativecommons.org/licenses/by/3.0/). 